Association for Information Systems AIS Electronic Library (AISeL)

1989

\title{
A FIELD-BASED INVESTIGATION INTO THE EFFECT OF EXPERT SYSTEM USE ON THE INFORMATION PROCESSING CAPACITY OF THE FIRM
}

John J. Sviokla

Harvard University

Follow this and additional works at: http://aisel.aisnet.org/icis 1989

\section{Recommended Citation}

Sviokla, John J., "A FIELD-BASED INVESTIGATION INTO THE EFFECT OF EXPERT SYSTEM USE ON THE INFORMATION PROCESSING CAPACITY OF THE FIRM" (1989). ICIS 1989 Proceedings. 52.

http://aisel.aisnet.org/icis1989/52 


\title{
A FIELD-BASED INVESTIGATION INTO THE EFFECT OF EXPERT SYSTEM USE ON THE INFORMATION PROCESSING CAPACITY OF THE FIRM
}

\author{
John J. Sviokla \\ Graduate School of Business Administration \\ Harvard University
}

\begin{abstract}
To date, there have been many reports on the use of decision support systems (DSS) and knowledgebased systems (KBS) in organizations. Little of this research evaluates the impact of commercial systems on the performance of the organization using the system. This study attempts to shed some light on this intellectual domain.

This paper reports on a field-based investigation into the effects of the use of MUDMAN ${ }^{\text {mI }}$ (a commercial expert systems product) on the information-processing capacity of N.L. Baroid, an oil services firm. The study uses the notions of organizational programs as defined by March and Simon and operationalizes the information processing capacity framework put forth by Galbraith to show how information-processing capacity was affected when the MUDMAN ${ }^{\text {th }}$ system was used at Baroid.
\end{abstract}

\section{INTRODUCTION}

Luconi, Malone, and Scott-Morton (1985) note three defining features of an expert system (ES). First, an ES uses special-purpose knowledge about a particular problem domain; second, it uses symbolic reasoning rather than only numeric calculation; and third, it performs better than nonexpert humans. In comparing ES, DSS, and Expert Support Systems (ESS), the authors distinguish four categories: data, procedures, goal/constraints, and strategies. In a DSS, the computer and the human share responsibilities for managing data, use of procedures, setting goals and constraints, but the problem-solving strategies are left to the human. In an expert support system, the computer shares the realm of flexible problemsolving strategies as well. For our purposes we will use the definition of an ESS, as defined by Luconi, Malone, and Scott-Morton, but for convenience we will call it an ES.

\subsection{Impacts of Expert Systems}

Michael Scott-Morton $(1967,1971)$ provided one of the very first studies of the impact of decision support systems (DSS). In a study of a laundry equipment manufacturer's use of a marketing/manufacturing DSS, he found that the system had a profound impact on the speed of the decisions and the detail of data considered. Moreover, he discovered that the system helped the organization communicate coherently and concisely about complex manufacturing and marketing trade-offs.

Since that time we have had books and articles on DSS (Alter 1980; Bennett 1983; Keen and Scott-Morton 1978) and, more recently, on ES (Harmon, Maus and Morrissey 1988; Feigenbaum, McCorduck and Nii 1988). (For a more extensive literature review, see Sviokla 1986.)
Despite the large number of reported cases and research articles, few investigators have chosen to focus on the effects the use of these tools have on the user organization. This article will focus on how the use of an expert system had an impact in one firm.

Scott-Morton (1984), perhaps as a result of his early work in an extensive review of over 300 articles on Management Support Systems (MSS), noted a lack of research into changes caused by MSS, saying "much work has been done on the impacts of traditional management information systems, but virtually nothing on the impacts of MSS" (p. 31).

In a more recent evaluation of the research literature in DSS, group DSS (GDSS) and ES, Benbasat and Nault (1988) found a similar hole in the intellectual fabric of the field. They categorized the literature into "design" and "effects of use" camps. Within the effects of use they found that most of the work had evaluated the effects of DSS and GDSS on the individual; however, "work on the effects of ES use is rare" (p. i). Thus despite a propitious beginning by one of the founders of the field -- a full twenty-one years ago -- few have endeavored to measure effects of our nontransaction MIS systems on the organization.

This research study approaches this problem by drawing on existing theories of information processing capacity (Galbraith 1973, 1977) and organizational programs (March and Simon 1958) to create rough measures as a guide to a field-based investigation.

\subsection{Methodology}

Benbasat, Goldstein and Mead (1986), in a review of case research in information systems, noted that one important 
motivation for case research occurs when "the research is interested in complex problems which cannot be removed from the setting without destroying the phenomenon" ( $p$. 7).

Bonoma (1985) advocates the use of case research in environments "where the existing body of knowledge is insufficient to permit the posing of causal questions, and when a phenomenon cannot be studied outside the context in which it naturally occurs" (p. 207).

Understanding how the use of an expert system has an impact on a firm's information-processing capacity is entwined with an understanding of the business process it is designed to support. Hence a case study seemed appropriate. Yet, to avoid "mindless empiricism" (Hauptmann 1989), two guiding measures were employed: organizational program maps and information-processing capacity.

\subsection{Definition of Measures}

The organizational program is operationalized by creating process-flow diagrams that map out the steps necessary to execute the task being examined. All flow diagrams have been generated by the author. (See Table 1 for a definition of task. (The sample unit for each site is the task organization, also defined in Table 1.)

\section{Table 1}

\section{Some Definitions}

- The task (or, the business task): The business task that the expert system is designed to support. For example, the task for PlanPower (a financial planning expert system) is "financial planning."

- The task onganization: The task organization is a group of individuals who are active in the creation and delivery of the product/service.

- The product: The product and/or service which the task is designed to create (in MUD planning, the MUD plan is one facet of the product).

The operationalization of the first measure, organizational programs, builds directly on March and Simon's (1958) notion of an organizational program:

Performance programs (or programs). We have seen that under certain circumstances the search and choice processes are very much abridged. At the limit, an environmental stimulus may evoke immediately from the organization a highly complex and organized set of responses.
Such a set of responses we call a performance program, or simply a program. For example, the sounding of the alarm gong in a fire station initiates such a program. So does the appearance of a relief applicant at a social worker's desk. So does the appearance of an automobile chassis in front of the work station of a worker on the assembly line.(p. 141).

Galbraith (1977) defines the information-processing capacity of an organization to be the diversity of the outputs, the number of different input resources, and the level of task performance. For example, an organization with a high diversity of outputs, a high level of task performance, and a large number of inputs, has a high level of information-processing capacity. The operationalization of the three components that make up informationprocessing capacity for this study are pragmatic and simple. Inputs are defined as the number of data sources used and people consulted in the delivery of the product or service (the product/service is defined in Table 1). Outputs are defined as the number of different versions of the product/ service. The level of task performance is the management's assessment of performance and any available objective measures. The author rated these measures within each site.

A second design factor was chosen to sharpen the focus on measuring impacts. In order to capture the effects of the ES use on the information-processing capacity and on organizational programs, a pre-post design was employed, that is, the behavior of the organization around a narrow task was compared before and after the use of the tool. The site (Baroid) was selected from a list of over 30 potential sites for three reasons. First, it had an expert system in routine use. (Routine use was defined as used at least once a day in a nontest decision context.) Second, the task had substantial tracking and tracing associated with it, so many documents addressing past decisions and their effects were available for examination. Third, the system addressed a nontrivial business problem.

The drawback of the Baroid site was that there were no active implementation efforts underway -- all sites that were going to use the system were already using it. Thus, the only "pre" implementation state available to the researcher was historical reconstruction. Due to the paper trail kept for the decision process, and the long experience of the managers involved in the study, the historical account was rich. Yet, the reliability of self reports is often suspect and two efforts review with participants and triangulation), discussed below, were used to bolster the veracity of the accounts to allow for pre-post comparison.

All data (25 interviews, five day-long site visits, and voluminous archival data) were gathered by the author. Having a single rater for all measures has its benefits and costs. On the one hand, the single observer is more likely to rate things in a similar manner and to be more consistent. On the other hand, single-viewpoint assessment may 
bias the data. Two methods in the data collection design are used to strengthen the reliability of the data: review of data with individuals in the user organization and triangulation. Yin (1984) and others (Bonoma 1985; Roethlisberger 1977) have advocated reviewing case materials with members of the organization under study as a means of checking impressions, perspectives, and facts. This method was employed.

The second reliability-enhancing measure, triangulation (Bonoma 1985; Jick 1979), is a technique using different types of data to triangulate on any particular claim or insight. Three types of data were collected to understand the nature of the task:

- interviews

- observation

- archival data

These multiple sources of data allow triangulation of the rater's interpretation. The combination of these methodological efforts attempt to counterbalance the singleobserver bias.

\section{THE COMPANY SETTING}

NL Baroid or (Baroid) ${ }^{1}$ was the largest division of NL Industries, a conglomerate which provides products and services to the oil and chemical industries. Baroid's 1985 revenues of $\$ 382.7$ million accounted for 27.9 percent of NL Industries' total of \$1.4 billion. Specializing in sales of drilling fluids both to the major oil companies, such as Exxon, Gulf, and Shell, and to smaller, independent producers, Baroid was the largest such supplier in the world.

The 1980s were years of boom and bust of the oil industry. In 1981, oil reached its highest price. Drilling became more active, with over 4,000 rigs in operation in the United States. From this high, the industry dropped to its postWWII low. Prices for crude oil in mid-1986 were near $\$ 10.00$ per barrel, threatening to go to $\$ 8.00$ or even to $\$ 6.00$. Drilling activity fell to less than 700 active wells in the United States.

Financial figures for Baroid show this industry plunge. In 1981 , its revenues were $\$ 709.7$ million; in $1985, \$ 382.7$ million -- a drop of $\mathbf{4 1 . 6}$ percent. During these four years, the company lost approximately half its employees and trimmed all budgets severely.

Technology leadership had played an important role in establishing Baroid as a industry leader. Some experts felt that many of the technical breakthroughs in drilling muds had occurred during the 1920-1960 time frame. Since then, most major oil-service companies carried a full line of muds. The basis for competition shifted from technology toward price. Service record, reputation, and expertise remained important buyer criteria, but customer focus on cost of the product intensified as drilling muds became more and more of a commodity.

\section{THE ISSUE: MUD ENGINEERING}

Mud engineering is often challenging. Rigs can cost up to $\$ 500,000$ per day to operate; thus, when one stops drilling, the financial pressure to resume drilling is tremendous. Mud engineers say that mud is "the first thing to be blamed" for any trouble because all aspects of exploratory drilling -- cutting, logging, casing -- occur in the presence of mud. Incorrect or inattentive mud management can lead to serious well problems such as a "stuck pipe" or a blowout. Unlike the romantic movie image, which often shows a happy rig crew applauding a geyser of oil, a blowout in the oil field can spew out drilling equipment, injure or kill well hands, and destroy millions of dollars worth of equipment. Many possible problems -- such as blowouts -- are usually foreshadowed by changes in the mud and an alert mud engineer can take preventive measures.

From the oil company's perspective, mud management is usually a relatively small percentage of its cost. An offshore well platform might spend $\$ 5$ to $\$ 20$ million on mud in a year. Generally, the cost of mud is approximately six to eight percent of the drilling operator's costs.

Even though mud costs are a small share of total costs, operators are conscious of any controllable expense and are always anxious to keep mud bills as low as possible. More important, good mud management can lead to a more efficient well being drilled, which can mean substantial savings in drilling costs. Furthermore, mud management influences overall well quality, which in turn can affect the value and volume of oil (or other substance) extracted at the surface.

In order to appreciate what MUDMAN was designed to do, it is helpful to understand the nature of the mud engineer's job. When drilling a well, drilling fluids are pumped down the center of the drill pipe, exit from nozzles on the drill bit, and circulate back up to the surface where they are monitored, cleaned, and recirculated.

Mud is usually a mixture of water, clay, weighting material, rare earths, and other chemicals. Mud engineers monitor and regulate the properties of the drilling fluids to influence the characteristics of the well being drilled, that is, the "bore hole" characteristics. Ideally, the drilling fluid is maintained to optimize a number of factors simultaneously:

- Hole clearing (the removal of cuttings)

- The suspension of cuttings and other material during interruptions in circulation

- The removal of sand and cuttings from the mud (done at the surface) 
- The prevention of caving and sloughing in the hole

- The control of subsurface pressures

Any one mud ingredient may help preserve a number of factors on this list simultaneously. For example, clay helps keep the cutting in suspension so that if the circulation of the mud stops for any reason, the drilling shavings may not fall down to the bottom of the bore hole and clog it. Clay and other solids in the mud create a veneer of sheathing on the wall of the hole, known as the wall cake, which helps to keep the hole from sloughing -- that is, from caving in. Another multiple-function ingredient is barite -- the most popular weighting material. Barite has a high specific gravity. Its weight helps to keep all fluids, gases, and other material from seeping into the hole from the surrounding geological formation. Barite is also relatively inert, so that it does not react with other materials it contacts.

The challenge for the mud engineer arises because the factors listed above are always changing. Depth of the well, changing strata being drilled through, and mechanical difficulties can all shift the mud properties. To keep the mud within desired parameters can take frequent adjustment.

\section{MUD ENGINEERING ORGANIZATIONAL PROGRAMS: PRE- AND POST-MUDMAN}

Mud management entails three basic steps:

1. Developing a mud plan ${ }^{2}$

2. On-site mud management

3. Producing a mud report

\subsection{Pre-MUdMAN: Developing a Mud Plan}

Generally, the oil-service company works with the drilling operator to design the mud plan, which describes what type of mud will be used at each different stage of the drilling. Previous drilling experience in that location is the primary information upon which the two participants draw when creating the plan. There is an art to creating effective mud plans because each well can have very different mud requirements. For instance, two wells drilled off the same drilling platform, in the same area, might have completely different geological formations which require different muds. Experience and judgment are important guides to the mud planning.

A mud plan designated all muds that were to be used, when they were to be used, and how they were to be used. Mud requirements changed depending on the depth of the well. For instance, when a drilling operation was in its early stages, progress was often easy. An operator might quickly drill down hundreds of feet below the earth's crust. As the hole drilled deeper, many factors became progressively more challenging. The weight of the drilling pipe, or drill string, increased as tons of steel tube pressed down into the bore hole. A good mud engineer combined experience in the field with a knowledge of mud engineering so that the probability of a smooth drilling operation was maximizing while the cost of the mud was minimized. See Figure 1 for a diagram of the pre-MUDMAN Mud Plan Organizational Program.

\subsection{Pre-MUDMAN: Mud Management On-Site}

The next responsibility on the mud engineer's list was mud management. Pre-MUDMAN, the mud engineer (ME)

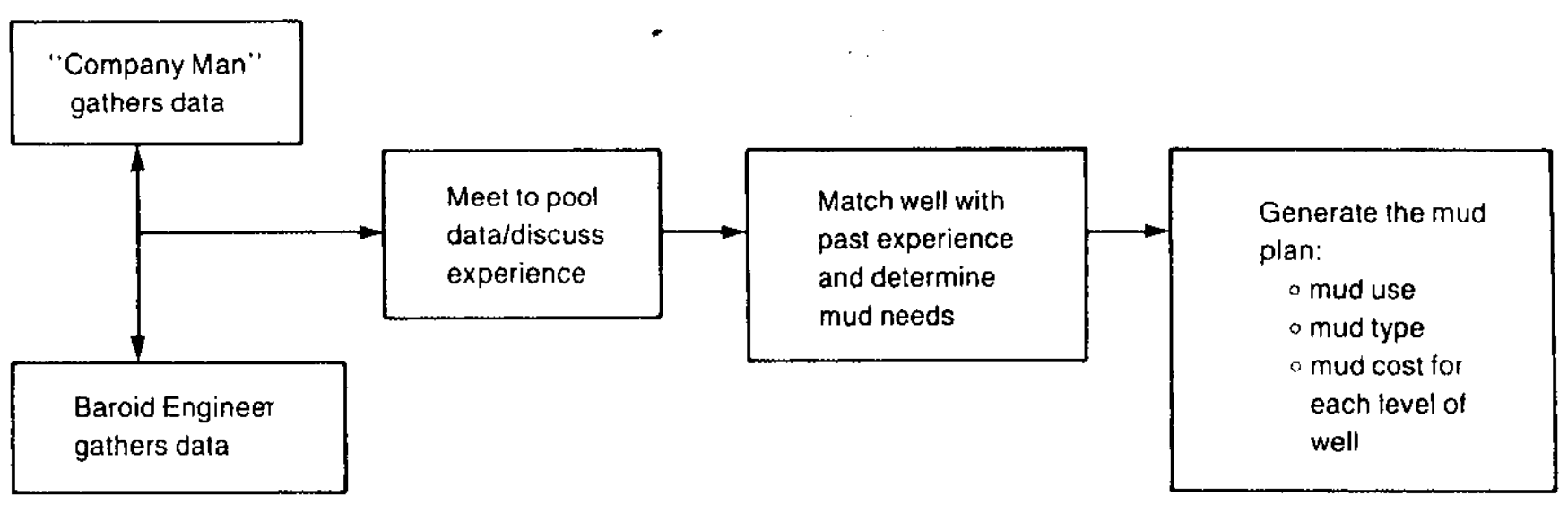

Figure 1. Pre-MUDMAN Mud Plan Organizational Program Map 
was isolated on the rig, conducting the mud tests, writing out a report, and sending it .. via mail or facsimile -- to the field office. (Facsimile use was relatively new and limited.) Sometimes, after submitting the report, the ME would call and check in with the office as well.

In order to determine what is happening hundreds or thousands of feet below the surface, the mud engineer monitors about 20 mud parameters -- such as density, solids content, and filtrate characteristics -- to see if they are within the expected values. There are many possible causes of deviation from desired levels: for example, the geology being drilled through can have mineral embedded in it which reacts with the mud; the drilling equipment can be circulating the mud poorly, ruining its chemistry; or the mud equipment itself might not be performing filtration correctly. Issues can arise as isolated incidents or they can interact to trigger even more complex challenges.
At least once per 24-hour day, the mud engineer gathers a bucket of mud to analyze in the mud-lab (which is always close at hand and usually on site). When problems are occurring, the mud can be sampled hourly, or more often, if necessary.

The likelihood of running into problems with the mud varies greatly with the type of well being drilled. Once a promising geological area is identified, one or more exploratory, or "wildcat," wells will be drilled in search of deposits. The term "wildcat" comes from the fact that in a new territory, a driller never knows exactly what will be encountered. For this same reason, mud management is especially challenging during exploration.

Problems on a rig could range from a minor fluctuation in the value of a mud parameter to "stuck pipe" or a blowout. Pre-MUDMAN, when a problem was encountered, the

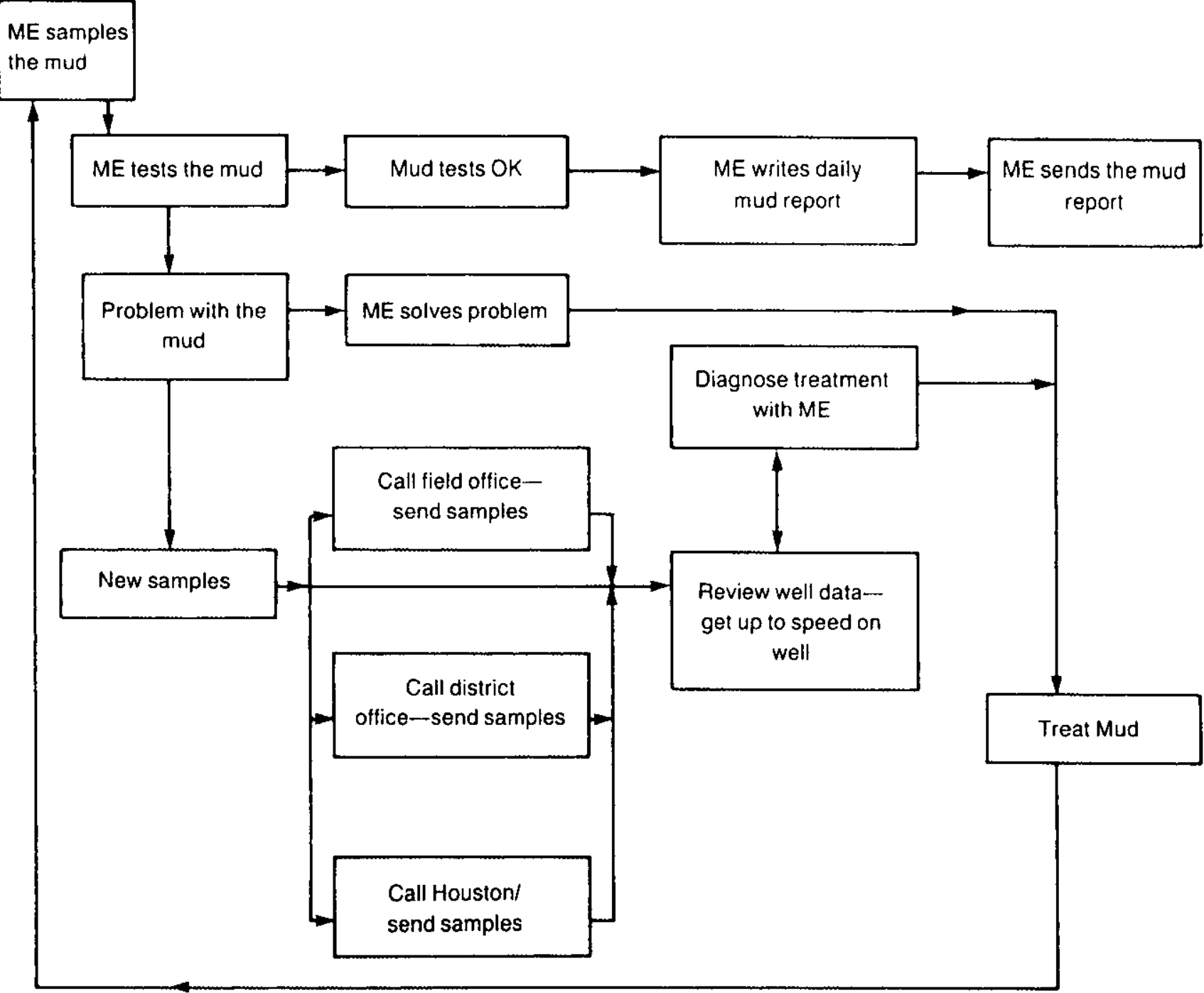

Figure 2. Pre-MUD Mud Management Organizational Program Map 
mud engineer usually took more mud samples and kept in closer contact with the field and district office. If a problem arose at the site, the first responsibility of the district managers was to obtain the most recent data about the well and make their own analyses. Often, the mud engineer would send samples to the field office for additional analysis. Escalation up Baroid's chain of command could occur almost immediately if the problem was severe enough; if necessary, test samples might be airshipped to the Houston labs. While the problem continued, consultations between the shore personnel and the $\mathrm{ME}$ on the rig occurred often as diagnoses were designed and treatments tried. The managers were kept informed about the results of each attempt. If necessary, more experienced engineers went to the site to assess the problem first-hand and to demonstrate to the customer that Baroid was willing to send its best people out on a problem if needed. See Figure 2 for a pre-MUDMAN Mud Management Organizational Program Map.

\subsection{Pre-MUDMAN: Mud-Reporting}

The last major ME responsibility, mud-reporting, which occurred at the end of the drilling, was to create a report that included all the daily logs, relevant billing, and accounting data about the well. The report compiled a complete and accurate record of the material used and detailed not only the types, volumes and costs of the mud, but analyzed the effectiveness of different mud treatments for different well issues. This document was usually 20 to 200 pages long, depending on the length of the well's operation. The tedious, exacting work on reports was the least favorite part of the ME's job, and it was not uncommon for a manager to remind a mud engineer to finish the mud report in a timely and complete manner. See Figure 3 for a pre-MUDMAN Mud-Reporting Organizational Program Map.

\subsection{MUDMAN: What it Does}

Baroid sells MUDMAN as a service to its customers for $\$ 350$ per day -- the same rate as it costs to hire a mud engineer. As the MUDMAN brochure states:

Designed to work with your Baroid technologist in analyzing and correcting downhole problems, MUDMAN is more than just a data-processing system. It's the first practical application of artificial intelligence in the drilling industry.

MUDMAN includes an expert system for drilling mud analysis, electronic mail facilities, a database to record mud data, an ability to perform complex calculations such as hydraulics analysis, and a report-generation facility for the creation of mud-analysis reports. The MUDMAN expert system performs three basic functions:

- data input;

- analysis of the data -- diagnosis of deviations from mud plan or previous mud values; and

- treatment recommendations. ${ }^{3}$

The mud engineer usually begins a session with MUDMAN by entering the new values for mud parameters. These can then be compared against either the mud plan or the previous mud values. The initial diagnosis is a simple list of those parameters that were off-target.

MUDMAN then diagnoses probable causes for these deviations from expected values. After analysis, the engineer can request treatment recommendations which give the specific quantities and types of mud to be added with reasons for their addition. At every point in the process, an explanation capability is available to tell why a particular diagnosis is indicated or a recommendation is given.

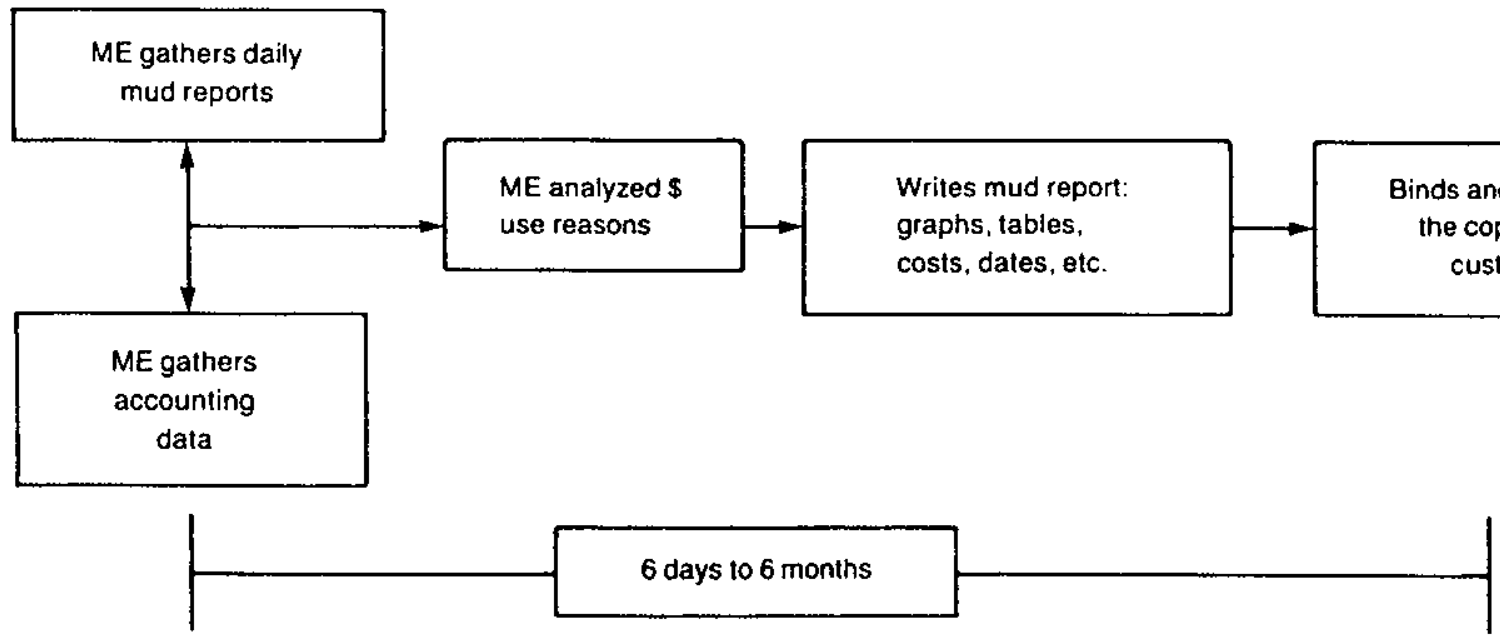

Figure 3. Pre-MUDMAN Mud-Reporting Organizational Program Map 
The software for MUDMAN was developed on a VAX $11 / 780^{\mathrm{TM}}$ and runs on Digital's Micro-VAX II $^{\mathrm{TM}}$ hardware. In general, a user dialed the Houston office in order to use MUDMAN, but it had been successfully tried remotely on a Micro-VAX II in the field as well. The program was written in a number of different computer languages, including LISP, BLISS, and OPS-5.

\subsection{Post-MUdMaN: Mud Engineering Program}

MUDMAN was first introduced on a nontest well in early spring 1985. The use of MUDMAN influenced all three aspects of the ME's job -- planning, management, and report writing.

In examining the effects of MUDMAN use it is helpful to recall that MUDMAN contains three basic elements: an ES to aid in mud engineering, a database, and a communications facility. The MUDMAN system is an integrated support and communications tool. Some of the effects of MUDMAN seemed caused by the ES component directly -- such as improved diagnostic capability. Yet, most of the effects seemed to be enabled by the ES, but were caused by the availability of the well data and diagnostic status which were readily communicated across the Baroid organization; that is, they were caused by the database and communications capabilities. This latter set of effects were facilitated by ES use, but not caused by it.

\subsection{Post-MUdMAN: Mud Planning}

In mud planning, MUDMAN gave better access to previous well data. One of the mud engineers in Louisiana using MUDMAN recounted an example:
Before MUDMAN, I kept my own records. A good mud engineer keeps good records. Where MUDMAN helps is that it makes the records more accessible. For example, there was some planning being done recently for a new well off a platform in an area where we had just finished a different well. The engineers creating that mud plan wanted to know what the weight of the mud was for a particular depth (drilling depth). In order to get that information they needed to find the daily reports for the other well and dig through them. It is more likely that, rather than searching out the old data, they would have relied on their previous experience to estimate the mud weight. With MUDMAN, they were able to call up the data needed and know the real numbers of the other well -- they liked that access.

In addition to the availability of the database, there was a facility in MUDMAN that helped the mud engineer design a mud plan from scratch. So far, MUDMAN's greatest influence on the mud planning part of the job seemed to come from the fact that data from the drilling of recent wells was readily accessible. The database of well information was generated through ongoing use of the MUDMAN diagnostic tool on different wells around the globe. Hence, the ES enabled the creation of the database, which in turn influenced the process of mud planning. See Figure 4 for the post-MUDMAN Mud Plan Organizational Program Map.

\subsection{Post-MUDMAN: Mud Management On-Site}

In post-MUDMAN mud management, for the second ME responsibility, the engineer still went through the same process of sampling the mud. However, instead of

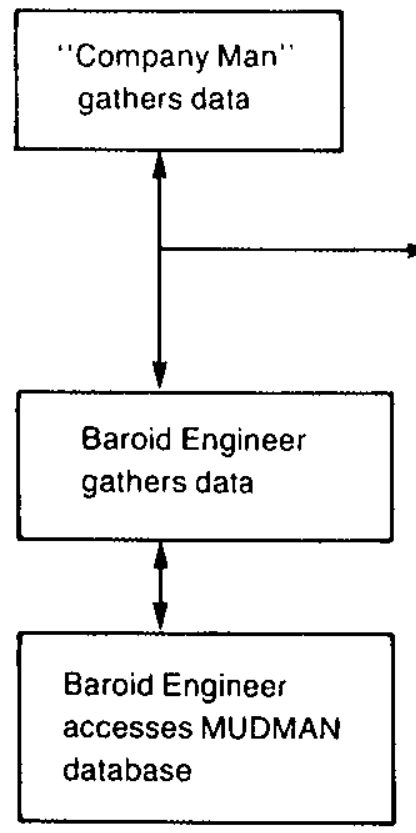

Figure 4. Post-MUDMAN Mud Plan Organizational Program Map 
reporting the data by hand on an American Petroleum Institute form and sending it via mail or facsimile to the field office, the data were entered into MUDMAN.

When the information was put into the system, the analysis and the data were available immediately to the shore management at the field office, the regional office, and headquarters (because the MUDMAN diagnostic program resided at Houston). All data were entered on remote terminals located on the wells. The MUDMAN data were accessible to all Baroid field sites using the proper password and security information. As a vice president for Drilling and Completion Services noted:

If I want to, I can call up the daily mud report first thing in the morning. Before, I would have to wait on the mud engineer to fill out his report and fax [send it by facsimile] to me -- or I could try to get the engineer on the phone. Generally I might keep tabs on sensitive or important wells so that if someone from the client company calls me and asks about the status of a given well, I can be right up to date and informed.

The daily facsimile usually went only to the field office responsible for the well except when it was requested by another manager. Managers reported that the communication of the analysis and well-status by MUDMAN meant that more people were informed on the day-to-day well situation sooner. This seemed to change the nature of problem reporting. For instance, when a problem arose, the engineering managers already were familiar with the specifics of the geology, mud, and recent drilling history of the well. Again, the ES part of MUDMAN provided the template to enter the status information and provided a diagnosis of the well situation. Yet it was the communication of this standardized data and diagnosis that affected the diagnostic procedure of Baroid because communication of the data kept more people better informed.

Because mud engineering was an "on-line" activity, time was often precious. The fact that other experts, back in the regional, district, and home offices, were more up to date and informed of the well status was considered a critical aid in quick and correct analysis and control of well problems. In effect, the importance of the change in reporting method was amplified by the pressure of the task. Furthermore, the mud engineers throughout the company could review MUDMAN's opinion of the situation so that they had a common diagnostic reference base in addition to common data upon which to build any further analysis or monitoring of the well.

Another useful feature of the MUDMAN expert system was simulation. It was possible to simulate a mud treatment so that when a mud engineer decided on the specific solution to the problem, he or she was able to enter the recommended treatment. With this information added to the current well data, MUDMAN could simulate the treatment and predict probable effects on the well. This gave the mud engineer the option of experimenting with mud treatments before actually performing the activity. According to one mud engineer, this simulation capability gave him more confidence in the mud analysis and treatment he recommended. See Figure 5 for the post-MUDMAN organizational program.

\subsection{Post-MUDMAN: Report Writing}

With MUDMAN, another benefit of the database part of the system was that interim reports were possible, daily recaps were also more readable and complete, and the summary reports could be drawn up only a few hours after a well reached the target depth. This last capability -- the ability to create a mud report rapidly -- was an important sales tool.

At the end of a well, the Baroid engineers wanted to be able to go to the customer and describe how the mud service went. When the job was done correctly, Baroid liked to show the "company man" the figures as soon as possible to let the customer know what a good job had been done. If the information was available immediately, it might influence the buyer to purchase Baroid products and services for another well, especially if more drilling was scheduled in the same area. If it took weeks or months to generate the report, much of the data's value might be lost. See Figure 6 for the Post-MUDMAN MudReporting Organizational Program Map.

As the director of the MUDMAN project explained:

The mud salesman would often be persona non grata at an oil company's office. They would not want to be bothered by oil service salesmen telling the same old tale. With the MUDMAN report, it gives our salesmen active and current information to bring to the oil company engineers. It helps us keep our contacts active and relationships current with daily reports and then with a prompt final report.

All three organizational programs -- mud planning, mud management, and mud reporting -- were significantly affected by the use of MUDMAN at Baroid. Where the organizational programs highlighted the process changes at the site, the organizational information processing measures try to assess the effect of MUDMAN use.

\section{POST-MUDMAN: INFORMATION PROCESSING CAPACITY}

We now move to the second measure of the impact of MUDMAN -- information-processing capacity. As mentioned earlier, Galbraith (1977) defines the informationprocessing capacity of an organization to be the diversity 


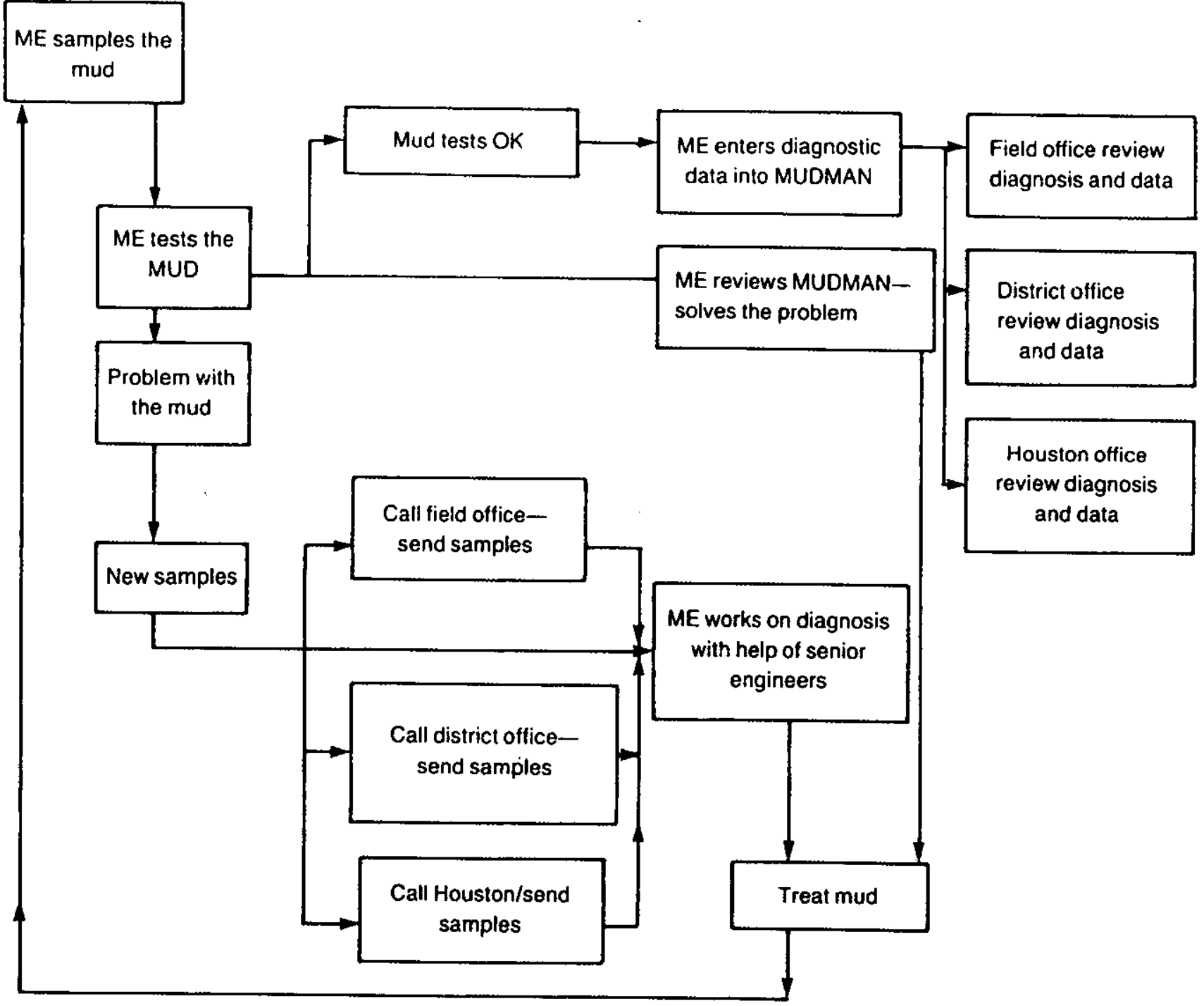

Figure 5. Post-MUDMAN Mud Management Organizational Program Map

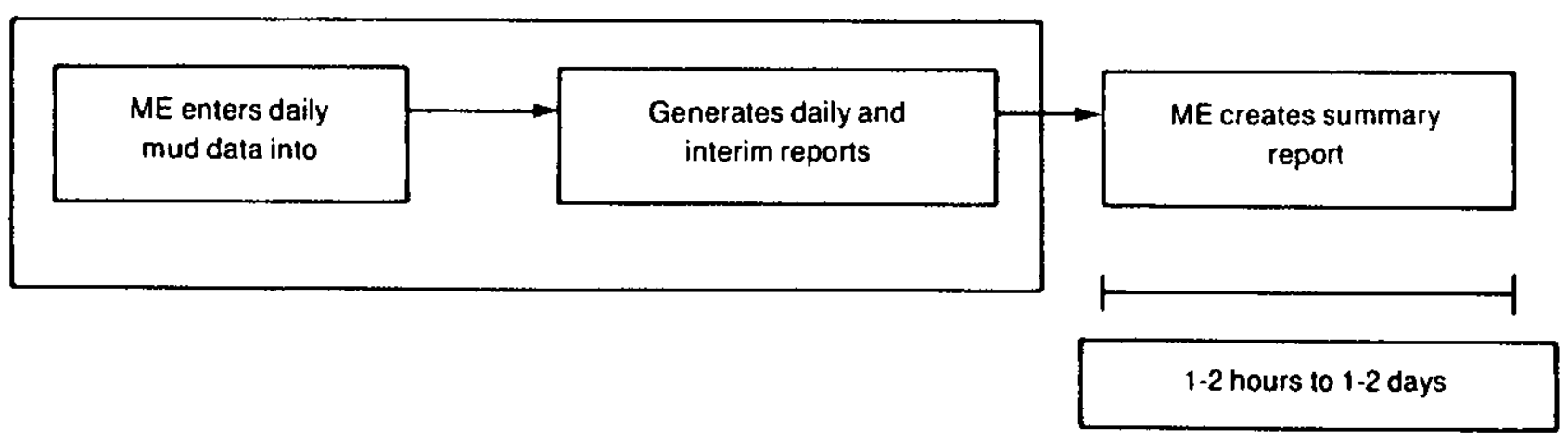

Figure 6. Post-MUDMAN Mud Report Organizational Program Map 
of the outputs, the number of different resources, and the level of task performance. As noted above, the determination of the information-processing capacity of the task organization at Baroid consisted of evaluating of the three components that make up information-processing capacity: inputs, outputs, and level of task performance.

In the MUDMAN case, there was evidence of increased information-processing capacity. The list of inputs, outputs, and task performance is shown in Table 2.

\subsection{Inputs}

Early use of the MUDMAN system revealed that there were a number of new inputs to the task of mud engineering. Figure 7 shows the chain of command from the well site back to the Houston headquarters. There were three mud engineering managers responsible for the ME's performance on the platform: the district manager, the regional manager, and the Houston office. These three offices had on-line access to the mud engineering situation. Mud engineering managers reported that they could keep abreast of the situation on the well.

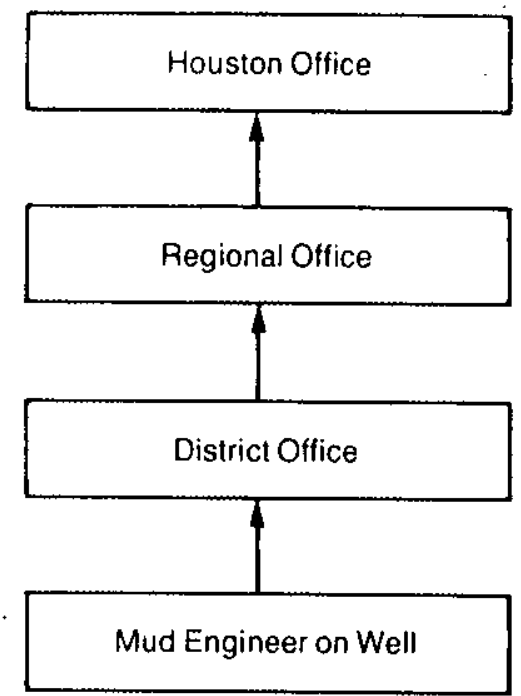

Figure 7. Baroid Chain of Command from Well Site to Houston Office

Table 2

\section{Pre-MUDMAN}

Inputs-Increase

- Mud engineer

- Previous well data

\section{Post-MUDMAN}

++ Mud engineer and mud-engineering management

++ Previous well data and trend data

++ MUDMAN

\section{Outputs-Increased}

- Mud plan

- API daily mud form

$$
\begin{aligned}
& =\text { Mud plan } \\
& + \text { More exact/accessible daily mud report } \\
& + \text { On-well support } \\
& ++ \text { Interim summaries and trend sheets }
\end{aligned}
$$

Task Performance-Significantly Increase

- At least one mud report per 12 -hour period
Daily reporting

- Finish mud report (1-20 weeks)
$=$ At least one mud report per 12-hour period

+ Daily reporting -- prompt/analysis now passed on

++ Better diagnosis -- four previously unsolved problems were solved using MUDMAN

++ Finish mud report faster (1 hour to 2-3 days)

The designations before each item on the list are indicators of the direction and the strength of the change in that category. For example $=$ is the same, ++ is strongly increased, - is decreased, etc. 
The increased involvement of the managers in review of the mud data meant that Baroid could be that much more effective in dealing with severe or immediate problems on the well because the extra experts were already informed about the well status and recent operations. This added involvement seemed to occur in the early MUDMAN wells. At the time of this study, it was not certain whether this improvement was temporary and caused by the novelty of the system, or if the effect would linger. It seems reasonable to assume that on difficult wells, the managers would avail themselves on the most up-to-date information available as part of their ongoing effort to keep informed about potential problems. Therefore, the effect could continue for the more challenging wells.

Concerning data, the mud engineers had on-line use of the trend analysis. In the diagnostic process of the expert system, MUDMAN indicated when the current mud parameters violated expected values. Expected values were based on the mud plans, which usually have a high and low value to bracket the desired value. In addition, there was an analysis of trend data and, even if a mud parameter were within its bracketed values, MUDMAN might issue a warning that a sharper-than-expected increase of one or more values of the mud parameters could indicate a potential problem. In this way, MUDMAN consistently analyzed historical data during mud diagnosis. Further, the mud engineer used more of the previous well data in the analyses because the data were readily available during the diagnosis phase of the session. Altogether, inputs to the mud engineering process increased -- some because of the $\mathrm{ES}$, some as a result of the database.

\subsection{Outputs}

The outputs in the form of daily reports and interim mud reports were more consistent and could be accessed faster. Pre-MUDMAN, a well would rarely have an interim report that detailed the muds used, their cost, and the symptoms encountered at the drilling site. Post-MUDMAN, it was common to create an interim report, both for use on the rig by the mud engineer talking with the operator on-site, and for use by Baroid sales people and service people when going to the oil company buying the service. The result was a new, on-going documentation and reporting of the well to both Baroid and the customer -- leading to an assessment that outputs from the process increased.

\subsection{Task Performance}

Pre-MUDMAN, it usually took anywhere from six weeks to six months to compile and write the mud report for the client. Much of the time was spent retrieving numbers, completing records, inventory, and resolving any discrepancies. For example, the inventory accounting records might not match the mud engineer's records of material, causing the $\mathrm{ME}$ to search painstakingly through every report to see what was wrong and why.
With MUDMAN the mud engineer found it easy to keep consistent daily records of all well and inventory information. As a result, when a drilling operation ended, compiling the mud report only took a few hours. The database created through use of the ES was complete and consistent. Consequently, it was not uncommon for a mud engineering manager to have the final mud report almost immediately and in a form ready to present to the customer.

Another major benefit was improved diagnosis of the well problems. The director of the MUDMAN project reported that, in four separate instances, MUDMAN had been integral in solving a previously unsolved diagnostic problem. The most dramatic example was on a well in the North Sea. Baroid's client was drilling a well experiencing a "carbonate problem" -- that is, carbonates were contaminating the mud. The drilling operator had been treating the carbonate problem on and off for ten years. A few days after the MUDMAN service was purchased for the well and the system was given a few days' worth of mud parameters, MUDMAN suggested that there might be a leakage of $\mathrm{CO}^{2}$ gas from the surrounding formation into the bore hole. At first, the drilling operator did not believe that this was the problem, but after investigation, $\mathrm{CO}^{2}$ was found to be the cause of the carbonate contamination. Once the correct diagnosis was reached, the remedy was clear -- raise the specific gravity of the mud to increase the mud weight sufficiently to drive the $\mathrm{CO}^{2}$ back into the formation surrounding the bore hole. This was done and the carbonate problem was solved. This evidence suggests that use of the MUDMAN expert system can improve the consistency and exactness of the mud diagnostic process. Use seemed to improve the execution of the organizational program, although a study of expert performance with and without the aid of MUDMAN would be necessary to show definitively that MUDMAN improved performance.

In addition to the observed increases in task performance, senior Baroid managers conjectured that MUDMAN use might increase the information-processing capacity of the entire mud engineering cadre by allowing more mud engineers to operate more effectively in the field. However, in 1986, the drilling industry was in such a deep depression that the potential for MUDMAN to help Baroid deal with peak needs, in terms of mud diagnostic capabilities, could not be tested until the market for oil rebounded. Even without a great increase in demand for mud services, the task performance for mud diagnosis seemed to have significantly increased from the preMUDMAN state to the post-MUDMAN state.

\section{SUMMARY}

This field study suggests that, in this company, site use of the MUDMAN system increased the information-processing capacity of the task organization performing the tasks of mud planning, mud management, and mud reporting. 
Much more work is needed to investigate the informationprocessing effects of system use in terms of the new information-processing tasks that use creates and the information-processing tasks it obviates. This single study, in one site, was only able to begin to explore these complexities.

\section{REFERENCES}

Alter, S. L. Decision Support Systems: Current Practices and Continuing Challenges. Reading, Massachusetts: Addison-Wesley, 1980.

Benbasat, I.; Goldstein, D.; and Mead, M. "The Case Research Strategy in Studies of Information Systems." Unpublished Paper. Harvard Business School, May 1986.

Benbasat, I., and Barrie R. N. "An Evaluation of Empirical Research in Managerial Support Systems." Working Paper, Faculty of Commerce and Business Administration, University of British Columbia. November 1988.

Bennett, J. L., Editor. Building Decision Support Systems. Reading, Massachusetts: Addison-Wesley, 1983.

Bonoma, T. V. "Case Research in Marketing: Opportunities, Problems, and a Process." Joumal of Marketing Research, Volume 22, May 1985, pp. 199-208.

Feigenbaum, E.; McCorduck, P.; and Nii, P. The Rise of The Expent Company. New York: Times Books, 1988.

Galbraith, J. Designing Complex Organization. Reading, Massachusetts: Addison-Wesley, 1973.

Galbraith, J. Organization 'Design. Reading, Massachusetts: Addison-Wesley, 1977.

Harmon, P.; Maus, R.; and Morrissey, W. Expert Systems: Tools and Applications. New York: Wiley \& Sons, 1988.

Hauptmann, O. "Different Roles of Communication in Software Development and Hardware R\&D: Phenomenological Paradox or Theoretical Empiricism?" Harvard Business School Working Paper, Number 89-028, 1989.

Jick, T. D. "Mixing Qualitative and Quantitative Methods: Triangulation in Action." Administrative Science Quarterly, Volume 24, December 1979, pp. 602-611.

Kahn, G., and McDermott, J. "The Mud System." IEEE Expent, Volume 1, Number 1, Spring 1986, pp. 23-32.
Keen, P. G. W., and Scott-Morton, M. Decision Support Systems: An Organizational Perspective. Reading, Massachusetts: Addison-Wesley, 1978.

Luconi, F.; Malone, T.; and Scott-Morton, M. S. "Expert Support Systems." CISR Working Paper, Number 122 Cambridge, Massachusetts, 1985.

March, J. G., and Simon, H. A. Organizations. New York: Wiley, 1958.

Roethlisberger, F. J. The Elusive Phenomena. Boston, Massachusetts: Division of Research, Harvard Business School, 1977.

Scott-Morton, M. S. The Effects of Computer Driven Visual Display Devices on Management. DBA Thesis, Harvard Business School, 1967.

Scott-Morton, M. S. Management Decision Systems: Computer Based Support for Decision Making. Boston, Massachusetts: Division of Research, Harvard Business School, 1971.

Scott-Morton, M. S. "The State of the Art of Research." In F. W. McFarlan, Editor, The Information Systems Research Challenge. Boston: Harvard Business School Press, 1984

Sviokla, J. J. PlanPower, XCON, and MUDMAN: An In-Depth Investigation Into Three Commercial Expert-Systems in Use. Unpublished Doctoral Dissertation, Harvard Business School, Boston, Massachusetts, 1986.

Yin, R. K. Case Study Research, Design and Methods, Beverly Hills: Sage Publications, 1984.

\section{ENDNOTES}

1. Baroid ${ }^{\mathrm{TM}}$ and MUDMAN ${ }^{\mathrm{TH}}$ are registered trademarks of NL Industries.

2. In the field it is actually called a "mud program," but here, as in Kahn and McDermott (1986), the term plan will be used to avoid confusion with software programs.

3. Kahn and McDermott co-developed MUDMAN for Baroid. See Kahn and McDermott (1986) for more details. 